\title{
Vesicle pools: lessons from adrenal chromaffin cells
}

\author{
David R. Stevens*, Claudia Schirra, Ute Becherer and Jens Rettig
}

Physiologisches Institut, Universität des Saarlandes, Homburg, Saarland, Germany

\section{Edited by:}

Robert Renden, UCB Pharma SA, Belgium

\section{Reviewed by:}

Maria Bykhovskaia, Universidad

Central del Caribe, Puerto Rico

Heidi De wit, Vrije Universiteit

Amsterdam, Netherlands

*Correspondence:

David R. Stevens, Physiologisches Institut, Universität des Saarlandes, Gebäude 59, Kirrberger Street 8, 66421 Homburg, Saarland, Germany. e-mail: phdste@uks.eu

\begin{abstract}
The adrenal chromaffin cell serves as a model system to study fast Ca2+dependent exocytosis. Membrane capacitance measurements in combination with $\mathrm{Ca} 2+$ uncaging offers a temporal resolution in the millisecond range and reveals that catecholamine release occurs in three distinct phases. Release of a readily releasable (RRP) and a slowly releasable (SRP) pool are followed by sustained release, due to maturation, and release of vesicles which were not release-ready at the start of the stimulus. Trains of depolarizations, a more physiological stimulus, induce release from a small immediately releasable pool of vesicles residing adjacent to calcium channels, as well as from the RRP.The SRP is poorly activated by depolarization. A sequential model, in which non-releasable docked vesicles are primed to a slowly releasable state, and then further mature to the readily releasable state, has been proposed. The docked state, dependent on membrane proximity, requires SNAP-25, synaptotagmin, and syntaxin. The ablation or modification of SNAP25 and syntaxin, components of the SNARE complex, as well as of synaptotagmin, the calcium sensor, and modulators such complexins and Snapin alter the properties and/or magnitudes of different phases of release, and in particular can ablate the RRP. These results indicate that the composition of the SNARE complex and its interaction with modulatory molecules drives priming and provides a molecular basis for different pools of releasable vesicles.
\end{abstract}

Keywords: large dense-core vesicles, docking, priming, releasable pools, SNARE complex

\section{INTRODUCTION}

Chromaffin cells from the adrenal medulla are ideally suited to distinguish and quantify the diverse pools of vesicles. They are, like postganglionic sympathetic neurons, derived from the neural crest and receive cholinergic input from preganglionic neurons of the splanchnic nerve. Since they also are excitable cells that generate action potentials, chromaffin cells are viewed as the endocrine counterparts of postganglionic sympathetic neurons and are often termed adrenal paraneurons. Sympathetic activation of chromaffin cells releases their hormones into the bloodstream in a $\mathrm{Ca}^{2+}$-dependent manner. The major molecules are the catecholamines, adrenaline, and noradrenaline, which regulate vascular tone, cardiac output, enteric activity, and insulin/glucagon release. Catecholamines are stored, together with chromogranin, neuropeptide $\mathrm{Y}$, and enkephalin, in large dense-core vesicles (LDCVs) with a diameter of about $120 \mathrm{~nm}$.

Large dense-core vesicle exocytosis from adrenal chromaffin cells shares many important features with neurotransmitter release from synaptic vesicles in classical CNS synapses. Both are $\mathrm{Ca}^{2+}$-dependent processes and are blocked by the action of tetanus and botulinum neurotoxins. The phenomena of two maturation steps preceding fusion, docking, and priming, are readily demonstrated in both neurons and chromaffin cells, and release occurs from a readily releasable pool (RRP) as described below. This release is carried out for the most part by proteins identical or very similar to those functioning at synapses (Burgoyne and Morgan, 1998), as described in the subsequent section on molecular determinants of pools.

However, there are also important differences between synaptic transmission and catecholamine secretion from chromaffin cells. Active zones, electron dense, protein rich areas with the attendant clusters of vesicles (Zhai and Bellen, 2004) are not obvious in chromaffin cells. The tight coupling of release sites with calcium entry sites (Zenisek et al., 2003) a hallmark of active zones, is not as well developed in chromaffin cells ( $\mathrm{Wu}$ et al., 2009). This is likely due to the lack of necessity of compartmentalization of release of LDCVs to an area opposite a postsynaptic membrane, since adrenal catecholamine release is endocrine in nature. For this reason, speed of release is also not paramount (Voets et al., 1999). LDCVs in neurons are not released at the active zones either (Hammarlund et al., 2008). Furthermore, rapid recycling of LDCVs does not appear to occur in chromaffin cells, most likely because the large number of existing LDCVs makes recycling unnecessary. Alternatively, recycling may be slowed in cultured chromaffin cells while still present in slices of adrenal glands.

Here we review the experimental results which shape our view of docked and releasable pools of vesicles in chromaffin cells and point out recent developments which shed light on the molecular background of these phenomena.

\section{THE DOCKED POOL}

Initial assays of docking in chromaffin cells concentrated on those vesicles which, in EM images, could be in contact with the plasma membrane, i.e., those within one vesicle diameter of the membrane, or on vesicles with visible contact to the plasma membrane. The former criterion likely overestimates docked vesicles while the latter will underestimate docked vesicles (Plattner et al., 1997). Inherent in this scheme is the idea that those vesicles which are not near the membrane build a large depot pool of vesicles which can be recruited as needed. 
Counts of docked vesicles indicate that the docked pool is much larger than the releasable pool (Parsons et al., 1995; Steyer et al., 1997). Thus, most docked vesicles are not releasable and must be primed (a maturation process) to become releasable. It is likely that primed vesicles will also reside in the docked pool. Methods are needed to distinguish releasable vesicles from unprimed vesicles in this docked pool.

Comparison of the number of morphologically docked vesicles with the number of vesicles that can be released by raising intracellular calcium led to the conclusion that though all docked vesicles could be released, only a fraction of the docked vesicles were readily releasable (Parsons et al., 1995). The distribution of LDCVs and small clear vesicles in bovine chromaffin cells has been described. Due to the density of vesicles, a number of vesicles will be in close apposition to the membrane and would be considered docked (Plattner et al., 1997). However the authors saw no compelling evidence for a preferentially docked population. When the analysis was repeated after either electrical stimulation to increase intracellular calcium and thus, enhance priming, or application of $70 \mathrm{mM}$ potassium extracellularly, to induce secretion, there was no obvious change in the numbers of morphologically docked vesicles, and it was concluded that either the releasable pool was not found in docked vesicles or the released vesicles were rapidly replaced by newly docked vesicles.

The docked population of vesicles may be obscured due to the high density of vesicles in adult bovine chromaffin cells (Plattner et al., 1997). In embryonic mouse chromaffin cells, vesicle density is lower and it is usual that vesicles collect near the cell membrane (Figure 1). Chromaffin cells from embryonic mice are quite often used, particularly in studies using genetic approaches, due to the perinatal lethality of mutations of many proteins involved in exocytosis.

The eccentric distribution of vesicles is not necessarily limited to morphological docking but can include a wider area adjacent to the membrane, perhaps indicating that not only vesicles contacting the membrane are restricted in their movement, consistent with findings in mouse motor nerve terminals (Gaffield et al., 2009). This may be related to a subplasmalemmal actin network which hinders the approach of vesicles to the membrane and thus may limit docking (Aunis and Bader, 1988). Munc18-1 may facilitate the movement of LDCVs into this actin rich zone (Toonen et al., 2006) where they may collect. This observation is likely related to the suggested role of actin in the recruitment of vesicles (Malacombe et al., 2006). The role of cytoskeletal elements in vesicle transport and release in chromaffin cells has been reviewed recently (Trifaro et al., 2008).

Application of high pressure freezing (HPF) techniques to samples for EM avoids artifacts of chemical fixation, limits freeze artifacts, and allows better preservation (Rostaing et al., 2006; Hammarlund et al., 2007). Vesicles that are visibly contacting the membrane can be readily observed under both conditions though the overall structure is better preserved by HPF (Figure 1). The exceptional structural preservation of HPF will provide more accurate estimates of docked vesicles and may allow distinction of subclasses of morphologically docked vesicles. This coupled with the use of the more rigorous requirement for visible contact between vesicles and the plasma membrane will produce lower estimates of the docked pool such that discrepancies between docked and the releasable pools are reduced, but it is unlikely that differences will entirely disappear.

Discrepancies between numbers of docked and primed vesicles may as well depend on the physiological conditions. For example, overexpression of Munc13-1 in bovine chromaffin cells caused a three-fold increase in the exocytotic burst, i.e., primed vesicles, with no effect on morphological docking (Ashery et al., 2000). The releasable dense-core vesicles ( 840) approached the upper estimates of docked vesicles in bovine chromaffin cells (Parsons et al., 1995; Plattner et al., 1997). If we accept the premise that primed vesicles reside in the docked pool, as discussed below, only a fraction $(\sim 1 / 3)$ of the docked vesicles would have been primed in the control cells. In addition, since priming is $\mathrm{Ca}^{2+}$-dependent, the intracellular $\mathrm{Ca}^{2+}$-concentration before and during fixation/ freezing will strongly influence the ratio between docked and primed vesicles.

The development of adequate markers for dense-core vesicles allows application of total internal reflection microscopy (TIRFM) to the question of vesicle behavior prior to exocytosis. TIRF imaging is limited to a layer about $200 \mathrm{~nm}$ deep adjacent to the plasma
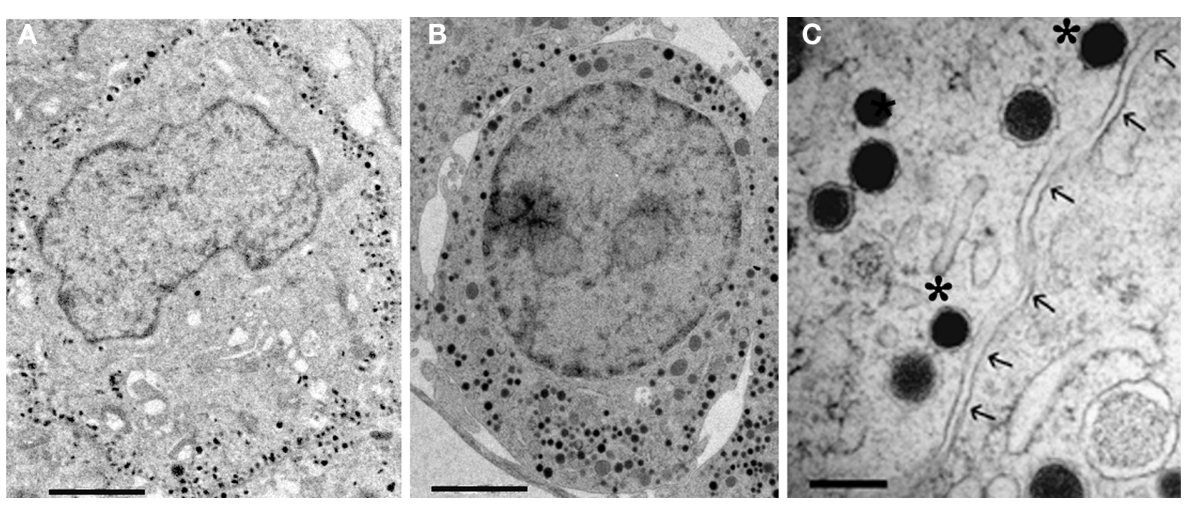

FIGURE 1 | Electron micrographs of embryonic mouse chromaffin cells (E19). (A) Chemically fixed chromaffin cell. (B) Unfixed chromaffin cell which was rapidly frozen under high pressure. (C) Detail of vesicles from a chromaffin cell after high pressure freezing. Two dense-core vesicles would be classified as docked $\left(^{*}\right)$ based on visible contact with the cell membrane (arrows). Scale bar: (A,B), $2 \mu \mathrm{m}$ (C), $250 \mathrm{~nm}$. 
membrane, and thus is near to the membrane, as are the docked vesicles observed in EM. The behavior of such vesicles is complex, with a variety of types of motion (Johns et al., 2001; Allersma et al., 2006). Though several studies indicated that in chromaffin cells, LDCVs decrease their mobility prior to release (Steyer and Almers, 1999; Oheim and Stuhmer, 2000) the relationship between mobility and docking or priming was not established. TIRFM has been used to asses docking of LDCVs in chromaffin cells (Toonen et al., 2006) and in neurons of C. elegans (Zhou et al., 2007). In these studies docking was associated with a decrease in the mobility of vesicles and a prolongation of dwell times close to the plasma membrane, which has been corroborated in other studies (Steyer et al., 1997; Toonen et al., 2006; Yizhar and Ashery, 2008).

\section{MEASURING RELEASABLE POOLS}

The description of releasable pools and their properties is dependent on the ability to activate and successfully measure release. At a few synapses, voltage-clamp of the presynaptic terminal has been carried out in order to determine if the presynaptic calcium currents remain constant (Llinas et al., 1981; Forsythe, 1994), but it was soon appreciated that even if calcium currents were uniform, the calcium signal in the terminal was not uniform due to strong concentration gradients near channels and an inhomogeneous distribution of calcium channels which leads to generation of calcium microdomains near channels (Chad and Eckert, 1984; Simon and Llinas, 1985). In addition, estimates of release are usually based on the postsynaptic response to released neurotransmitter which can lead to errors due to receptor saturation, desensitization, and failure of transmitter to reach postsynaptic receptors.

Problems of non-homogeneity of the calcium signal have been overcome by the use of photo-release of caged calcium at the Calyx of Held (Bollmann et al., 2000; Schneggenburger and Neher, 2000; Felmy et al., 2003), a brainstem synapse with a very large presynaptic terminal, at other large synapses, e.g., the goldfish bipolar terminal (Heidelberger et al., 1994), in pituitary melanotrophs (Thomas et al., 1993), and in adrenal chromaffin cells (Heinemann et al., 1994).

The adrenal chromaffin cell has a number of advantages for the examination of vesicle pools. Though larger than most presynaptic terminals, they are spherical with no extended processes. Thus whole cell recording and the associated exchange of pipette contents with the intracellular compartment, a requirement for application of photo-releasable $\mathrm{Ca}^{2+}$ for stimulation, are greatly facilitated. Voltage-clamp allows measurement of vesicle release via changes in cell capacitance (solving the problems of estimating release from postsynaptic responses) and can be combined with direct assay of released catecholamines via amperometry, providing two independent measures of secretion. In addition, TIRFM allows the visualization of vesicles at the plasma membrane and thus enables the correlation between vesicle mobility and priming status.

\section{RELEASABLE POOLS IN CHROMAFFIN CELLS}

Using depolarizations of differing duration, Horrigan and Bookman (1994) found that there was an initial rapidly released pool which they called the immediately releasable pool (IRP) and a large, more slowly released pool they named the RRP in bovine chromaffin cells, consisting of about 17 and 170 vesicles, respectively. When chromaffin cells were stimulated at $18 \mathrm{~Hz}$ with $10 \mathrm{~ms}$ depolarizing pulses, release was biphasic (Voets et al., 1999). A small, immediately releasable component was followed by a much larger releasable pool. These two components were better distinguished using a train of six short $(10 \mathrm{~ms})$ depolarizations followed by four long (200 ms) depolarizations at $3.3 \mathrm{~Hz}$, which activate the IRP and the RRP, respectively.

Flash photolysis of caged calcium produces a rapid, stepwise increase in intracellular free calcium, and triggers an exocytotic burst (Heinemann et al., 1994). This burst occurs in the first second after flash stimulation and can be well fit as the sum of two exponentials with time constants of $20-40 \mathrm{~ms}$ and circa $300 \mathrm{~ms}$, respectively. The burst is followed by a sustained phase of release (see Figure 2). Though RRP and slowly releasable pool (SRP) have similar calcium sensitivities, the rate of release from the SRP is consistent with a slower binding rate for calcium, indicating that vesicles in the SRP may utilize a different calcium sensor (Voets, 2000; Sorensen, 2004). Both components approach a plateau in the first second after stimulation, though the calcium concentration remains high, indicating that both pools are depleted.

By combining depolarization and flash stimulation, it has been shown that the rapid component of the burst is the same pool that can be released by high frequency stimulation or a series of four $100 \mathrm{~ms}$ depolarizations to near $0 \mathrm{mV}$, corresponding to the RRP (Voets et al., 1999). An IRP is not observed in flash experiments. The IRP appears to be due to a population of vesicles in the RRP which resides quite near to calcium entry sites and thus releases earlier in mild depolarization protocols (Voets et al., 1999). Vesicles of the IRP are not more release-ready than the rest of the RRP. Depolarization protocols can deplete the RRP and under these conditions, the rapid component of flash photolysis is strongly depressed. Conversely, flash photolysis effectively depletes the releasable pools activated by depolarization.

Depolarization protocols are not effective in depleting the SRP. When depletion of the RRP, via depolarization, is followed by flash photolysis, the exocytotic burst releases as a single component with a time constant expected for the SRP. After RRP depletion, recovery, as evidenced by responses to four $200 \mathrm{~ms}$ depolarizations at $3 \mathrm{~Hz}$, occurs over about $20 \mathrm{~s}$. When the SRP is tested by flash photolysis parallel to tests for recovery of the RRP, the recovery of the RRP is accompanied by a decrease of similar magnitude in the SRP, indicating the refilling of the RRP occurs at the expense of the SRP. This led to the conclusion that though vesicles in the SRP are releasable, they mature to the RRP as the result of a further priming step.

The above results indicate a sequential process in which docked vesicles are primed to a slowly releasable state and then mature further to a readily releasable state (Voets et al., 1999). This model has been formalized in a recent review (Sorensen, 2004). The model, based to a large extent on the experiments from mouse chromaffin cells described above, suggests that in the exemplary mouse chromaffin cell a reserve pool of $\sim 2000$ vesicles is present, as is a docked pool of $\sim 787$ vesicles. The numbers of vesicles in the SRP and RRP, which all reside in the docked pool, are dependent on the resting calcium concentration. The numbers range from $\sim 38$ to $\sim 45$ vesicles, respectively, at low $[\mathrm{Ca} 2+]_{\mathrm{i}}(200 \mathrm{nM})$, and approaching 200 vesicles in each pool at high basal $[\mathrm{Ca} 2+]_{\mathrm{i}}(\sim 700 \mathrm{nM})$. 

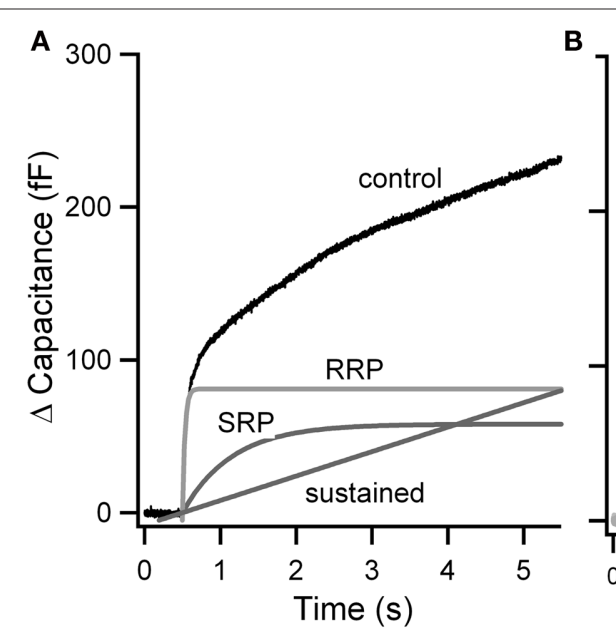

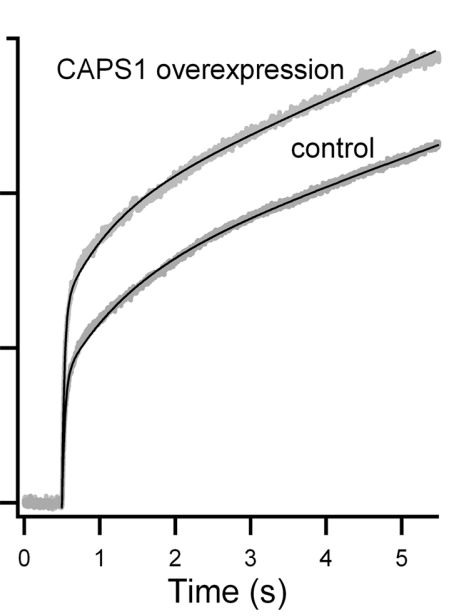

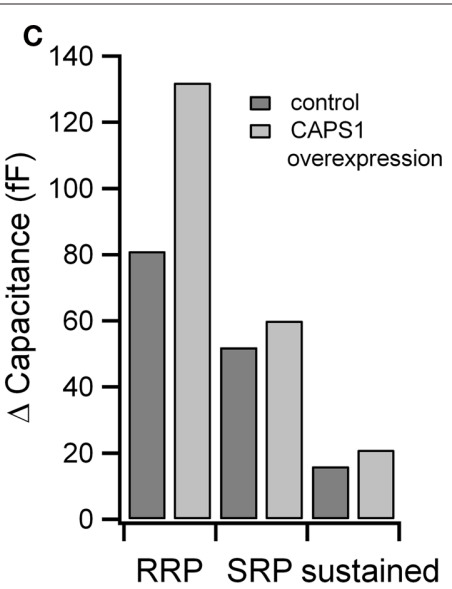

FIGURE 2 | Estimate of pool size from flash experiments. (A) Averaged flash response from embryonic mouse chromaffin cells. Resting cells were stimulated using flash photolysis of NP-EGTA at $0.5 \mathrm{~s}$. The resulting capacitance increase (control) is shown. RRP, SRP, and the sustained component of the response estimated from fits of traces to the sum of two exponentials and a linear phase are shown. (B) Example experimental application: flash responses and fits (black) of control cells and cells overexpressing CAPS1 (data from Liu et al., 2008). (C) Comparison of the size of RRP, SRP, and sustained component in control and CAPS1 overexpressing cells.
When flash photolysis was carried out with lower post-flash free calcium levels $(<5 \mu \mathrm{M})$, a small, rapid component of secretion was observed which has been called the highly calcium-sensitive pool (HCSP, Yang and Gillis, 2004). This pool is enhanced by the activation of protein kinase $\mathrm{C}$. Since activity-dependent increases in intracellular calcium activate PKC, the HCSP may be important in use-dependent plasticity of catecholamine release and may be released by low level stimulation or by release of intracellular calcium stores. Combination with depolarization protocols have convincingly demonstrated that this pool is not identical to the IRP previously described. The HCSP releases rapidly at calcium concentrations at which the RRP releases relatively slowly.

Following the exocytotic burst, there is sustained release of vesicles at a low rate as long as the calcium stimulus remains at required levels (within limits). This is considered to be due to the priming of vesicles which at the time of the stimulus were not yet primed. It has been argued that sustained release occurs from the SRP (Sorensen, 2004). Thus sustained release is not a product of a unique pool of vesicles, but rather the product of ongoing priming into the releasable pool(s).

Since vesicle exocytosis can be observed in TIRFM, the activity of the vesicles immediately prior to the exocytosis can be ascribed to the primed state. Immediately prior to release, vesicles appear to become immobile (Toonen et al., 2006; Nofal et al., 2007) and enhancement of priming may lead to a higher probability of this immobile state (Nofal et al., 2007).

\section{THE MOLECULAR DETERMINANTS OF POOLS}

A current emphasis is the identification of the molecular basis of the various pools of vesicles. A number of accessory proteins have been suggested which modulate both docking and the priming steps. There has been rapid progress on a number of fronts. SNARE proteins are central to the process of exocytosis and play a role in both docking and priming. SNARE proteins may function in docking as part of a docking complex (see Docking below).
In concert with synaptobrevin, a vesicle-membrane associated SNARE protein, syntaxin, and SNAP-25 form a ternary complex, the SNARE complex, that drives the fusion of plasma membrane and vesicle lipid bilayers allowing exocytosis of vesicle contents (see reviews; Sudhof, 2004; Sudhof and Rothman, 2009). The primed state requires partial assembly of this ternary complex (see Releasable State below).

\section{DOCKING}

Rab3's are members of a large group of small GTPases which function in membrane fusion reactions (Malsam et al., 2008). Rabs associate with vesicle membranes and in combination with their effectors tether vesicles near release sites, facilitating docking in neurons and neuroendocrine cells (Jahn et al., 2003). Rabphilins have been proposed as Rab partners in vesicle recruitment in chromaffin cells, based on the secretion enhancing effects of expression in PC12 cells (Tsuboi and Fukuda, 2005) and chromaffin cells (Chung et al., 1995).

Munc18-1 (a homolog of the yeast sec-1 protein) binds to Rab3 (Graham et al., 2008) and appears to be required for Rab3 enhancement of docking (van Weering et al., 2007) and is itself required for docking (see next paragraph). If Rab3 initiates tethering of LDCVs at the cell membrane, this occurs upstream of, but would facilitate SNARE-dependent docking. A function of Rab3 upstream of Munc18-1's docking function has been proposed in chromaffin cells (van Weering et al., 2007).

Munc18-1 is also required for docking of vesicles in neurons and in neuroendocrine cells, via its association with syntaxin. Knockout of Munc18-1 leads to a strong reduction in morphologically docked vesicles (Voets et al., 2001b; Weimer et al., 2003). There is a strong correlation between Munc18 function, vesicle dwell time, and jitter of tethered vesicles in TIRFM experiments (Toonen et al., 2006) in embryonic mouse chromaffin cells. Arrival of vesicles at the membrane was also strongly reduced in experiments with Munc18-1 deleted as opposed to wild type cells, but this 
effect was not syntaxin dependent. Reintroduction of Munc18-1 restores morphological docking as well as reversing the effects of Munc18-1 deletion on dwell time and arrival at the membrane in TIRFM. However, Munc18's role appears to go beyond docking since it is involved in both membrane attachment, subsequent SNARE complex formation, in priming and in exocytosis (GulyasKovacs et al., 2007; Deak et al., 2009).

The original discovery of the SNAP receptor (SNARE) proteins syntaxin, VAMP/synaptobrevin and SNAP-25 was accompanied by the suggestion that these molecules could explain the phenomenon of membrane docking in exocytosis (Sollner et al., 1993). Though this proposal was rapidly supported by experimental results (Pevsner and Scheller, 1994; Pevsner et al., 1994), reports that treatment with bacterial toxins which selectively cleave SNARE proteins suppressed synaptic transmission but failed to reduce docking, raised doubts (Hunt et al., 1994; Broadie et al., 1995; see review Hanson et al., 1997).

It has been reported that SNAP-25 is not required for docking (Graham et al., 2001; Sorensen et al., 2002). In addition, the deletion of synaptobrevin is not associated with a loss of docking (Borisovska et al., 2005). These results support the conclusion that SNARE proteins are not required for docking (Becherer and Rettig, 2006).

In contrast, genetic approaches have provided evidence that syntaxin deletion strongly reduces docking in C. elegans (Hammarlund et al., 2007, 2008) and in mouse chromaffin cells (de Wit et al., 2006). Recently, SNAP-25 deletion in mouse chromaffin cells was also shown to result in a severe loss of docking, which could be rescued by reintroduction of SNAP-25 (de Wit et al., 2009). Thus synaptobrevin may be the only SNARE protein not required for docking in chromaffin cells.

If synaptobrevin is not involved in docking, a candidate for a vesicle associated protein with a docking function is synaptotagmin. The perseverance of docking after toxin treatment has been attributed to the additional binding of synaptotagmin (Schiavo et al., 1997). Its C2A domain appears to interact with vesicle membranes (Radhakrishnan et al., 2009). Deletion of synaptotagmin-1 produced a strong docking defect in mouse chromaffin cells, as did expression of soluble tandem C2AB peptides (de Wit et al., 2009) which bind to SNAP-25/syntaxin SNARE acceptor complexes (Fasshauer and Margittai, 2004) and thus displace endogenous synaptotagmin-1. Rescue by wild type synaptotagmin but not by SNARE binding deficient mutants corroborate the conclusion that synaptotagmin-1 is involved in docking (de Wit et al., 2009).

The above results are consistent with a model in which syntaxin/SNAP-25 complexes accept vesicles at docking sites. Synaptotagmin-1 initiates the docking of vesicles at this complex. This process is coordinated by Munc18's. The occurrence of dramatic docking phenotypes from which normal fusion events (and thus priming) occur, though at much lower frequency, strengthens the argument that a specific docking mechanism exists with requirements other than those for priming (Verhage and Sorensen, 2008). As expected, strong docking phenotypes are associated with release deficits as well, consistent with the idea that primed vesicles reside in, or are generated from, the docked vesicle pool.

\section{THE PRIMED POOL(S)}

There is ample evidence that exocytosis is dependent on formation of the SNARE complex and thus all releasable pools must be dependent on SNARE complex formation (Sudhof, 1995). A number of manipulations of SNARE proteins can also alter the rate of release. In general, these manipulations strongly reduce release, but may block release of the RRP while leaving the SRP functional. Deletion of synaptobrevin-1 and -2 in chromaffin cells leads to an almost complete loss of secretion (Borisovska et al., 2005), as does deletion of SNAP-25 (Sorensen et al., 2003) and syntaxin (de Wit et al., 2006). Clostridial toxins are highly specific proteases that cleave SNAP-25, syntaxins, or synaptobrevins (Schiavo et al., 1993). Botulinum neurotoxin A cleaves the final nine amino acids of SNAP-25 and causes a selective block of the RRP in chromaffin cells (Sorensen et al., 2003).

In SNAP-25 knockout mice, normal secretion can be restored by expression of SNAP-25 (Sorensen et al., 2003). These results indicate that though SNAP-23 can replace SNAP-25 in secretion in chromaffin cells, the SNAP-23 containing primed SNARE complex is less stable and unprimes readily and thus does not support an RRP. Expression of the cleavage product of Botulinum neurotoxin A restores secretion, but this release resembles the SRP. Thus, deletion of the final nine amino acids produces a SNARE protein (SNAP$25 \Delta 9$ ) that supports the SRP but does not support either the RRP or the HCSP (Yang et al., 2002). Since zippering of the SNARE motifs is likely a requirement for any secretion (Hanson et al., 1997; Sorensen et al., 2006; Bretou et al., 2008; Stein et al., 2009; Jackson, 2010; Wiederhold et al., 2010) the ( $\Delta 9)$ truncation of SNAP-25 does not appear to prevent complex formation or zippering but rather alters the interaction of components of the complex. Mutations affecting the C-terminal interactions of the SNARE bundles alter the kinetics of fusion, while $\mathrm{N}$-terminal mutations prevent priming (Walter et al., 2010). Thus, priming depends on partial assembly of the ternary SNARE complex and unlike docking, is dependent on the association of synaptobrevin with the syntaxin/Snap-25 acceptor complex.

Synaptotagmin-1 is the calcium sensor for rapid regulated exocytosis in some neurons (Koh and Bellen, 2003; Nagy et al., 2006). Its deletion in chromaffin cells leaves the SRP intact but completely blocks rapid release (Voets et al., 2001a). The $\Delta-9$ truncation of SNAP-25 alters the calcium-dependent binding of synaptotagmin-1 (Gerona et al., 2000) and ablates the RRP. Thus the interaction of synaptotagmin with the SNARE complex may well be altered by the truncation of the C-terminal nine amino acids of SNAP-25. Synaptotagmin-1 can be replaced by synaptotagmin-2 in chromaffin cells with no loss of function, although secretion is slightly slowed when synaptotagmin-2 is present (Nagy et al., 2006). Synaptotagmin-7 is also present in chromaffin cells and contributes to normal secretion (Schonn et al., 2008), generating a slower component of release than that mediated synaptotagmin-1. Thus synaptotagmin-7 is likely to be responsible for the slower secretion observed in synaptotagmin-1 knockout chromaffin cells. These results show that synaptotagmins also play a role in the kinetics of release. It has been suggested that synaptotagmin might be involved in forcing the two membranes together, in conjunction with SNARE complex zippering (Arac et al., 2006). 
When synaptotagmin-1 is overexpressed in chromaffin cells, there is an enhancement of the RRP with a subsequent loss of secretion from the SRP, consistent with the results of RRP recovery experiments (see above; Voets, 2000), indicating filling of the RRP from the SRP. Alternatively, the interplay between the RRP and SRP could indicate that there are a limited number of release complexes and that promotion of the RRP reduces the availability of these sites for SRP complexes, though this seems unlikely since the primed pool, though much smaller than the docked pool under normal conditions, can be greatly increased by overexpression of Munc13-1 (see below).

Snapin is another modulatory protein of SNARE complexes which binds to SNAP-25 in vitro (Ilardi et al., 1999). It may stabilize the interaction between synaptotagmin and the SNARE complex (Tian et al., 2005). Loss of Snapin selectively reduces the RRP with no effect on its kinetics or on the SRP. Expression of Snapin in mouse chromaffin cells lacking Snapin restores the RRP while overexpression of Snapin in wild type mouse chromaffin cells enhances the RRP. Thus Snapin appears to modulate the efficiency of SNARE triggering by synaptotagmin-1.

The complexins modulate exocytosis by interacting with syntaxin-synaptobrevin complexes (Chen et al., 2002) and modulate the availability of releasable pools. Mixed results have appeared concerning the role of complexins (Brose, 2008). In neurons, complexins appear to play dual roles, promoting the releasable state (Reim et al., 2001) perhaps by promoting a supercoiled high energy conformation while also clamping the SNARE complex so that premature spontaneous fusion cannot occur (Tang et al., 2006).

A recent study in chromaffin cells expressing no complexin protein demonstrated that in their absence, exocytosis is reduced with no preference for RRP or SRP, and that neither morphological docking nor release rates were changed (Cai et al., 2008). The lack of enhanced secretion following deletion of complexin may indicate that complexins are not required as fusion clamps in chromaffin cells. The reason for this may be that the primed SNARE complex is not held at as high an energy state as that in neurons (Brose, 2008). This would explain the observed lack of spontaneous fusion in chromaffin cells as well as the failure of hyperosmolar solution to release the vesicles in chromaffin cells. Thus complexin would promote priming by enhancing SNARE complex formation but does not factor in releasable pool differentiation in chromaffin cells.

Munc13's and calcium activator protein for secretion (CAPS) are considered priming factors. Munc13's are involved in priming of synaptic vesicles at many synapses (Brose et al., 2000) and have been shown to enhance both the SRP and RRP in chromaffin cells with no effect on morphological docking (Ashery et al., 2000). Munc13 is thought to act by unfolding syntaxin 1 to its open form, allowing SNARE complex formation (Dulubova et al., 1999). Deletion of Munc13-1 can be overcome by expression of a mutated form of syntaxin which takes on the open conformation (Richmond et al., 2001). Overexpression of Munc13-1 in chromaffin cells produces a three- to four-fold increase in the exocytotic burst but does not alter the balance between SRP and RRP. Enhancement of priming via Munc13-1 overexpression led to an increase in highly immobile vesicles in bovine chromaffin cells observed by TIRFM, indicating that these highly immobile vesicles are primed (Nofal et al., 2007). This is in agreement with the release readiness of "strongly tethered," immobile vesicles (Toonen et al., 2006; Nofal et al., 2007). Since primed vesicles interact with the membrane via a ternary SNARE complex it is expected that they would exhibit less mobility than docked but unprimed vesicles in which synaptobrevin is not yet incorporated in a SNARE complex. The lack of mobility of primed vesicles should come as no surprise since priming involves formation of the ternary SNARE complex, and likely involves formation of multiple SNARE complexes.

Calcium-dependent activator protein for secretion has also been proposed as a priming factor in neurons (Jockusch et al., 2007) and neuroendocrine cells (Stevens and Rettig, 2009), though there is disagreement as to whether CAPS docks or primes. While in $C$. elegans CAPS deletion appears to alter docking (Zhou et al., 2007; Hammarlund et al., 2008), no effects on morphological docking are observed in chromaffin cells (Speidel et al., 2005; Liu et al., 2008).There is a clear reduction of flash photolysis induced secretion in CAPS1-2 knockout chromaffin cells (Liu et al., 2008). In these cells, the SRP remained normal while the RRP was strongly reduced, as was sustained release. Rescue using wild type CAPS1 protein restores both the RRP and sustained release. CAPS has been recently reported to interact with syntaxin as well as with SNARE complexes in various stages of assembly (Daily et al., 2010). CAPS deletion can also be partially overcome by expression of open syntaxin (Liu et al., 2010). Although CAPS can selectively promote priming of the RRP, priming to the RRP proceeds to some degree in the absence of CAPS, indicating that CAPS function in priming is facilitatory.

Since Munc13-1 increases the exocytotic burst (Ashery et al., 2000) while CAPS selectively primes to the RRP in chromaffin cells (Liu et al., 2008), priming is a two step process. Munc13's may work upstream of CAPS, though there is no direct evidence that endogenous Munc13's function in chromaffin cell priming. The ability of CAPS to promote preferentially the RRP indicates function at the priming step into the RRP, the only position in a linear scheme where such a preferential effect on the RRP can occur.

\section{CONCLUSION}

Experiments in adrenal chromaffin cells have demonstrated unequivocally the presence of multiple releasable pools of LDCVs. When global, stepwise increases in calcium concentration are used to trigger release, so that differences in local concentration of the calcium trigger are avoided, three releasable pools with different rates of release can be activated. A large reserve pool exists from which several hundred vesicles are observed to be in a morphologically docked state. The status of vesicles is dependent on the presence and activity of numerous docking and priming molecules.

The SNARE proteins syntaxin 1 and SNAP-25 provide an acceptor site to which vesicle-bound synaptotagmin attaches, in a docking event, orchestrated by Munc18-1 (de Wit et al., 2009), producing close apposition to the plasma membrane. The majority of docked vesicles are normally not primed although stimulation of priming may allow the primed pool to approach the size of the docked pool (see above). Improved methods are needed to answer the question of identity between morphologically docked and primed pools, as well as that of the relevance of results from TIRFM to the morphologically docked vesicles of EM. 
Priming appears to consist of SNARE complex formation, with the association of synaptobrevin with the syntaxin/SNAP-25 docking complex. Since a number of manipulations can alter the RRP without affecting the SRP, there are indeed molecular differences between these two pools. Vesicles mature to the SRP, perhaps under the influence of Munc13's and then prime to the RRP, promoted by CAPS. The RRP is the physiologically releasable pool, and thus the priming step to the RRP can be considered to be true priming.

\section{REFERENCES}

Allersma, M. W., Bittner, M. A., Axelrod, D., and Holz, R. W. (2006). Motion matters: secretory granule motion adjacent to the plasma membrane and exocytosis. Mol. Biol. Cell 17, 2424-2438.

Arac, D., Chen, X., Khant, H. A., Ubach, J., Ludtke, S. J., Kikkawa, M., Johnson, A. E., Chiu, W., Sudhof, T. C., and Rizo, J. (2006). Close membrane-membrane proximity induced by $\mathrm{Ca}(2+)-$ dependent multivalent binding of synaptotagmin-1 to phospholipids. Nat. Struct. Mol. Biol. 13, 209-217.

Ashery, U., Varoqueaux, F., Voets, T., Betz, A., Thakur, P., Koch, H., Neher, E., Brose, N., and Rettig, J. (2000). Munc13-1 acts as a priming factor for large dense-core vesicles in bovine chromaffin cells. EMBO J. 19, 3586-3596.

Aunis, D., and Bader, M. F. (1988). The cytoskeleton as a barrier to exocytosis in secretory cells. J. Exp. Biol. 139, 253-266.

Becherer, U., and Rettig, J. (2006). Vesicle pools, docking, priming, and release. Cell Tissue Res. 326, 393-407.

Bollmann, J.H., Sakmann, B., and Borst, J. G. (2000). Calcium sensitivity of glutamate release in a calyx-type terminal. Science 289, 953-957.

Borisovska, M., Zhao, Y., Tsytsyura, Y., Glyvuk, N., Takamori, S., Matti, U., Rettig, J., Sudhof, T., and Bruns, D. (2005). v-SNAREs control exocytosis of vesicles from priming to fusion. EMBO J. 24, 2114-2126.

Bretou, M., Anne, C., and Darchen, F. (2008). A fast mode of membrane fusion dependent on tight SNARE zippering. J. Neurosci. 28, 8470-8476.

Broadie, K., Prokop, A., Bellen, H. J., O'Kane, C. J., Schulze, K. L., and Sweeney, S. T. (1995). Syntaxin and synaptobrevin function downstream of vesicle docking in Drosophila. Neuron 15, 663-673.

Brose, N. (2008). For better or for worse: complexins regulate SNARE function and vesicle fusion. Traffic 9, 1403-1413.

Brose, N., Rosenmund, C., and Rettig, J. (2000). Regulation of transmitter release by Unc-13 and its homologues. Curr. Opin. Neurobiol. 10, 303-311.
Burgoyne, R. D., and Morgan, A. (1998). Analysis of regulated exocytosis in adrenal chromaffin cells: insights into NSF/SNAP/SNARE function. Bioessays 20, 328-335.

Cai, H., Reim, K., Varoqueaux, F., Tapechum, S., Hill, K., Sorensen, J. B., Brose, N., and Chow, R. H. (2008). Complexin II plays a positive role in $\mathrm{Ca} 2+$-triggered exocytosis by facilitating vesicle priming. Proc. Natl. Acad. Sci. U.S.A. 105, 19538-19543.

Chad, J.E., and Eckert, R. (1984). Calcium domains associated with individual channels can account for anomalous voltage relations of CA-dependent responses. Biophys. J. 45, 993-999.

Chen, X., Tomchick, D. R., Kovrigin, E., Arac, D., Machius, M., Sudhof, T. C., and Rizo, J. (2002). Three-dimensional complex. Neuron 33, 397-409.

Chung, S. H., Takai, Y., and Holz, R. W. (1995). Evidence that the Rab3abinding protein, rabphilin3a, enhances regulated secretion. Studies in adrenal chromaffin cells. J. Biol. Chem. 270, 16714-16718.

Daily, N. J., Boswell, K. L., James, D. J., and Martin, T.F. (2010). Novel interactions of CAPS (Ca2+-dependent activator protein for secretion) with the three neuronal SNARE proteins required for vesicle fusion. J. Biol. Chem. 285, 35320-35329.

de Wit, H., Cornelisse, L. N., Toonen, R. F., and Verhage, M. (2006). Docking of secretory vesicles is syntaxin dependent. PLOS ONE 1, e126. doi: 10.1371/ journal.pone. 0000126

de Wit, H., Walter, A. M., Milosevic, I., Gulyas-Kovacs, A., Riedel, D., Sorensen, J. B., and Verhage, M. (2009). Synaptotagmin-1 docks secretory vesicles to syntaxin-1/SNAP-25 acceptor complexes. Cell 138, 935-946.

Deak, F., Xu, Y., Chang, W. P., Dulubova, I., Khvotchev, M., Liu, X., Sudhof, T. C., and Rizo, J. (2009). Munc18-1 binding to the neuronal SNARE complex controls synaptic vesicle priming. J. Cell Biol. 184, 751-764.

Dulubova, I., Sugita, S., Hill, S., Hosaka, M., Fernandez, I., Sudhof, T. C., and Rizo, J. (1999). A conformational switch in syntaxin during exocytosis: role of munc18. EMBO J. 18, 4372-4382. structure of the complexin/SNARE

The RRP is apparently refilled from the SRP, thus the SRP may be a source of rapidly primable vesicles, similar to the role played by the recycling pool in neurons, when secretion is high.

\section{ACKNOWLEDGMENTS}

Research in our lab has been funded by several grants from the Deutsche Forschungsgemeinschaft and by competitive, local funding HOMFOR, University of the Saarland.

Fasshauer, D., and Margittai, M. (2004). A transient $\mathrm{N}$-terminal interaction of SNAP-25 and syntaxin nucleates SNARE assembly. J. Biol. Chem. 279, 7613-7621.

Felmy, F., Neher, E., and Schneggenburger R. (2003). The timing of phasic transmitter release is $\mathrm{Ca} 2+$-dependent and lacks a direct influence of presynaptic membrane potential. Proc. Natl. Acad. Sci. U.S.A. 100, 15200-15205.

Forsythe, I. D. (1994). Direct patch recording from identified presynaptic terminals mediating glutamatergic EPSCs in the rat CNS, in vitro. J. Physiol. 479(Pt 3), 381-387.

Gaffield, M. A., Tabares, L., and Betz, W. J. (2009). Preferred sites of exocytosis and endocytosis colocalize during high- but not lower-frequency stimulation in mouse motor nerve terminals. J. Neurosci. 29, 15308-15316.

Gerona, R. R., Larsen, E. C., Kowalchyk, J. A., and Martin, T. F. (2000). The C terminus of SNAP25 is essential for $\mathrm{Ca}(2+)$-dependent binding of synaptotagmin to SNARE complexes. J. Biol. Chem. 275, 6328-6336.

Graham, M. E., Handley, M. T., Barclay, J. W., Ciufo, L. F., Barrow, S. L., Morgan, A., and Burgoyne, R. D. (2008). A gainof-function mutant of Munc18-1 stimulates secretory granule recruitment and exocytosis and reveals a direct interaction of Munc18-1 with Rab3. Biochem. J. 409, 407-416.

Graham,M.E., Washbourne, P., Wilson, M. C., and Burgoyne, R. D. (2001). SNAP25 with mutations in the zero layer supports normal membrane fusion kinetics. J. Cell Sci. 114, 4397-4405.

Gulyas-Kovacs, A., de Wit, H., Milosevic, I., Kochubey, O., Toonen, R., Klingauf, J., Verhage, M., and Sorensen, J. B. (2007). Munc18-1: sequential interactions with the fusion machinery stimulate vesicle docking and priming. J. Neurosci. 27, 8676-8686.

Hammarlund, M., Palfreyman, M. T., Watanabe, S., Olsen, S., and Jorgensen, E. M. (2007). Open syntaxin docks synaptic vesicles. PLoS Biol. 5, e198. doi: 10.1371/journal.pbio.0050198

Hammarlund, M., Watanabe, S., Schuske, K., and Jorgensen, E. M. (2008). CAPS and syntaxin dock dense core vesicles to the plasma membrane in neurons. J. Cell Biol. 180, 483-491.
Hanson, P. I., Heuser, J. E., and Jahn, R. (1997). Neurotransmitter release four years of SNARE complexes. Curr. Opin. Neurobiol. 7, 310-315.

Heidelberger, R., Heinemann, C., Neher, E., and Matthews, G. (1994). Calcium dependence of the rate of exocytosis in a synaptic terminal. Nature 371, 513-515.

Heinemann, C., Chow, R. H., Neher, E., and Zucker, R. S. (1994). Kinetics of the secretory response in bovine chromaffin cells following flash photolysis of caged Ca2+. Biophys. J. 67, 2546-2557.

Horrigan, F. T., and Bookman, R. J. (1994). Releasable pools and the kinetics of exocytosis in adrenal chromaffin cells. Neuron 13, 1119-1129.

Hunt, J. M., Bommert, K., Charlton, M. P., Kistner, A., Habermann, E., Augustine, G. J., and Betz,H. (1994).A post-docking role for synaptobrevin in synaptic vesicle fusion. Neuron 12, 1269-1279.

Ilardi, J. M., Mochida, S., and Sheng, Z. H. (1999). Snapin: a SNARE-associated protein implicated in synaptic transmission. Nat. Neurosci. 2, 119-124.

Jackson, M. B. (2010). SNARE complex zipping as a driving force in the dilation of proteinaceous fusion pores. $J$. Membr. Biol. 235, 89-100.

Jahn, R., Lang, T., and Sudhof, T. C. (2003). Membrane fusion. Cell 112, 519-533.

Jockusch, W. J., Speidel, D., Sigler, A., Sorensen, J. B., Varoqueaux, F., Rhee, J.S., and Brose, N. (2007). CAPS-1 and CAPS-2 are essential synaptic vesicle priming proteins. Cell 131, 796-808.

Johns, L. M., Levitan, E. S., Shelden, E. A., Holz, R. W., and Axelrod, D. (2001). Restriction of secretory granule motion near the plasma membrane of chromaffin cells. J. Cell Biol. 153 177-190.

Koh, T. W., and Bellen, H. J. (2003). Synaptotagmin I, a Ca2+ sensor for neurotransmitter release. Trends Neurosci. 26, 413-422.

Liu, Y., Schirra, C., Edelmann, L., Matti, U., Rhee, J., Hof, D., Bruns, D., Brose, N., Rieger, H., Stevens, D. R., and Rettig, J. (2010). Two distinct secretory vesiclepriming steps in adrenal chromaffin cells. J. Cell Biol. 190, 1067-1077.

Liu, Y., Schirra, C., Stevens, D. R., Matti, U., Speidel, D., Hof, D., Bruns, D., 
Brose, N., and Rettig, J. (2008). CAPS facilitates filling of the rapidly releasable pool of large dense-core vesicles. J. Neurosci. 28, 5594-5601.

Llinas, R., Steinberg, I. Z., and Walton, K. (1981). Relationship between presynaptic calcium current and postsynaptic potential in squid giant synapse. Biophys. J. 33, 323-351.

Malacombe, M., Bader, M. F., and Gasman, S. (2006). Exocytosis in neuroendocrine cells: new tasks for actin. Biochim. Biophys. Acta 1763, 1175-1183.

Malsam, J., Kreye, S., and Sollner, T. H. (2008). Membrane fusion: SNAREs and regulation. Cell. Mol. Life Sci. 65, 2814-2832.

Nagy, G., Kim, J. H., Pang, Z. P., Matti, U., Rettig, J., Sudhof, T. C., and Sorensen, J. B. (2006). Different effects on fast exocytosis induced by synaptotagmin 1 and 2 isoforms and abundance but not by phosphorylation. J. Neurosci. 26, 632-643.

Nofal, S., Becherer, U., Hof, D., Matti, U., and Rettig, J. (2007). Primed vesicles can be distinguished from docked vesicles by analyzing their mobility. $J$. Neurosci. 27, 1386-1395.

Oheim, M., and Stuhmer, W. (2000). Tracking chromaffin granules on their way through the actin cortex. Eur. Biophys. J. 29, 67-89.

Parsons, T. D., Coorssen, J. R., Horstmann, H., and Almers, W. (1995). Docked granules, the exocytic burst, and the need for ATP hydrolysis in endocrine cells. Neuron 15, 1085-1096.

Pevsner, J., Hsu, S. C., Braun, J. E., Calakos, N., Ting, A. E., Bennett, M. K., and Scheller, R. H. (1994). Specificity and regulation of a synaptic vesicle docking complex. Neuron 13, 353-361.

Pevsner, J., and Scheller, R. H. (1994). Mechanisms of vesicle docking and fusion: insights from the nervous system. Curr. Opin. Cell Biol. 6, 555-560.

Plattner, H., Artalejo, A. R., and Neher, E. (1997). Ultrastructural organization of bovine chromaffin cell cortex-analysis by cryofixation and morphometry of aspects pertinent to exocytosis. J. Cell Biol. 139, 1709-1717.

Radhakrishnan, A., Stein, A., Jahn, R., and Fasshauer, D. (2009). The Ca2+ affinity of synaptotagmin 1 is markedly increased by a specific interaction of its $\mathrm{C} 2 \mathrm{~B}$ domain with phosphatidylinositol 4,5-bisphosphate. J. Biol. Chem. 284, 25749-25760.

Reim, K., Mansour, M., Varoqueaux, F., McMahon, H. T., Sudhof, T. C., Brose, N., and Rosenmund, C. (2001). Complexins regulate a late step in Ca2+-dependent neurotransmitter release. Cell 104, 71-81.

Richmond, J. E., Weimer, R. M., and Jorgensen, E.M. (2001). An open form of syntaxin bypasses the requirement for UNC-13 in vesicle priming. Nature 412, 338-341.

Rostaing, P., Real, E., Siksou, L., Lechaire, J. P., Boudier, T., Boeckers, T.M., Gertler, F., Gundelfinger, E. D., Triller, A., and Marty, S. (2006). Analysis of synaptic ultrastructure without fixative using high-pressure freezing and tomography. Eur. J. Neurosci. 24, 3463-3474.

Schiavo, G., Santucci, A., Dasgupta, B. R., Mehta, P. P., Jontes, J., Benfenati, F., Wilson, M. C., and Montecucco, C. (1993). Botulinum neurotoxins serotypes A and E cleave SNAP-25 at distinct $\mathrm{COOH}$-terminal peptide bonds. FEBS Lett. 335, 99-103.

Schiavo, G., Stenbeck, G., Rothman, J. E., and Sollner, T. H. (1997). Binding of the synaptic vesicle v-SNARE, synaptotagmin, to the plasma membrane t-SNARE, SNAP-25, can explain docked vesicles at neurotoxin-treated synapses. Proc. Natl. Acad. Sci. U.S.A. 94, 997-1001.

Schneggenburger, R., and Neher,E. (2000). Intracellular calcium dependence of transmitter release rates at a fast central synapse. Nature 406, 889-893.

Schonn, J. S., Maximov, A., Lao, Y., Sudhof, T. C., and Sorensen, J. B. (2008). Synaptotagmin-1 and -7 are functionally overlapping $\mathrm{Ca} 2+$ sensors for exocytosis in adrenal chromaffin cells. Proc. Natl. Acad. Sci. U.S.A. 105, 3998-4003.

Simon, S. M., and Llinas, R. R. (1985). Compartmentalization of the submembrane calcium activity during calcium influx and its significance in transmitter release. Biophys. J. 48, 485-498.

Sollner, T., Whiteheart, S. W., Brunner, M., Erdjument-Bromage, H., Geromanos, S., Tempst, P., and Rothman, J. E. (1993). SNAP receptors implicated in vesicle targeting and fusion. Nature 362, 318-324.

Sorensen, J. B. (2004). Formation, stabilisation and fusion of the readily releasable pool of secretory vesicles. Pflugers Arch. 448, 347-362.

Sorensen, J. B., Matti, U., Wei, S. H., Nehring, R. B., Voets, T., Ashery, U., Binz, T., Neher, E., and Rettig, J. (2002). The SNARE protein SNAP-25 is linked to fast calcium triggering of exocytosis. Proc. Natl. Acad. Sci. U.S.A. 99, 1627-1632.

Sorensen, J. B., Nagy, G., Varoqueaux, F., Nehring, R. B., Brose, N., Wilson, M. C., and Neher, E. (2003). Differential control of the releasable vesicle pools by SNAP-25 splice variants and SNAP23. Cell 114, 75-86.

Sorensen, J. B., Wiederhold, K., Muller, E. M., Milosevic, I., Nagy, G., de Groot, B. L., Grubmuller, H., and Fasshauer, D. (2006). Sequential N- to C-terminal
SNARE complex assembly drives priming and fusion of secretory vesicles. EMBO J. 25, 955-966.

Speidel, D., Bruederle, C. E., Enk, C., Voets, T., Varoqueaux, F., Reim, K., Becherer, U., Fornai, F., Ruggieri, S., Holighaus, Y., Weihe, E., Bruns, D., Brose, N., and Rettig, J. (2005). CAPS1 regulates catecholamine loading of large dense-core vesicles. Neuron 46, 75-88.

Stein, A., Weber, G., Wahl, M. C., and Jahn, R. (2009). Helical extension of the neuronal SNARE complex into the membrane. Nature 460, 525-528.

Stevens, D. R., and Rettig, J. (2009). The $\mathrm{Ca}(2+)$-dependent activator protein for secretion CAPS: do I dock or do I prime? Mol. Neurobiol. 39, 62-72.

Steyer, J. A., and Almers, W. (1999). Tracking single secretory granules in live chromaffin cells by evanescentfield fluorescence microscopy. Biophys. J. 76, 2262-2271.

Steyer, J. A., Horstmann, H., and Almers, W. (1997). Transport, docking and exocytosis of single secretory granules in live chromaffin cells. Nature 388, 474-478.

Sudhof, T. C. (1995). The synaptic vesicle cycle: a cascade of protein-protein interactions. Nature 375, 645-653.

Sudhof, T. C. (2004). The synaptic vesicle cycle. Annu. Rev. Neurosci. 27, 509-547.

Sudhof, T. C., and Rothman, J. E. (2009). Membrane fusion: grappling with SNARE and SM proteins. Science 323 474-477.

Tang, J., Maximov, A., Shin, O. H., Dai, H., Rizo, J., and Sudhof, T. C. (2006). A complexin/synaptotagmin 1 switch controls fast synaptic vesicle exocytosis. Cell 126, 1175-1187.

Thomas, P., Wong, J. G., and Almers, W. (1993). Millisecond studies of secretion in single rat pituitary cells stimulated by flash photolysis of caged $\mathrm{Ca} 2+$ EMBO J. 12, 303-306.

Tian, J. H., Wu, Z. X., Unzicker, M., Lu, L., Cai, Q., Li, C., Schirra, C., Matti, U., Stevens, D., Deng, C., Rettig, J., and Sheng, Z. H. (2005). The role of Snapin in neurosecretion: snapin knock-out mice exhibit impaired calcium-dependent exocytosis of large dense-core vesicles in chromaffin cells. J. Neurosci. 25, 10546-10555.

Toonen, R. F., Kochubey, O., de Wit, H., Gulyas-Kovacs, A., Konijnenburg, B., Sorensen, J. B., Klingauf, J., and Verhage, M. (2006). Dissecting docking and tethering of secretory vesicles at the target membrane. EMBO J. 25 , 3725-3737.

Trifaro, J. M., Gasman, S., and Gutierrez, L. M. (2008). Cytoskeletal control of vesicle transport and exocytosis in chromaffin cells. Acta Physiol. (Oxf.) 192, 165-172.
Tsuboi, T., and Fukuda, M. (2005). The C2B domain of rabphilin directly interacts with SNAP-25 and regulates the docking step of dense core vesicle exocytosis in PC12 cells. J. Biol. Chem. 280, 39253-39259.

van Weering, J. R., Toonen, R. F., and Verhage, M. (2007). The role of Rab3a in secretory vesicle docking requires association/dissociation of guanidine phosphates and Munc18-1. PLoS ONE 2, e616. doi: 10.1371/journal. pone.0000616

Verhage, M., and Sorensen, J. B. (2008). Vesicle docking in regulated exocytosis. Traffic 9, 1414-1424.

Voets, T. (2000). Dissection of three Ca2+dependent steps leading to secretion in chromaffin cells from mouse adrenal slices. Neuron 28, 537-545.

Voets, T., Moser, T., Lund, P. E., Chow, R. H., Geppert, M., Sudhof, T. C. and Neher, E. (2001a). Intracellular calcium dependence of large densecore vesicle exocytosis in the absence of synaptotagmin I. Proc. Natl. Acad. Sci. U.S.A. 98, 11680-11685.

Voets, T., Toonen, R. F., Brian, E. C., de Wit, H., Moser, T., Rettig, J., Sudhof, T. C. Neher, E., and Verhage, M. (2001b). Munc18-1 promotes large dense-core vesicle docking. Neuron 31, 581-591.

Voets, T., Neher, E., and Moser, T. (1999). Mechanisms underlying phasic and sustained secretion in chromaffin cells from mouse adrenal slices. Neuron 23 , 607-615.

Walter, A. M., Wiederhold, K., Bruns, D., Fasshauer, D., and Sorensen, J. B. (2010). Synaptobrevin N-terminally bound to syntaxin-SNAP-25 defines the primed vesicle state in regulated exocytosis. J. Cell Biol. 188, 401-413.

Weimer, R. M., Richmond, J. E., Davis, W. S., Hadwiger, G., Nonet, M. L., and Jorgensen, E. M. (2003). Defects in synaptic vesicle docking in unc-18 mutants. Nat. Neurosci. 6, 1023-1030.

Wiederhold, K., Kloepper, T.H., Walter, A. M., Stein, A., Kienle, N., Sorensen, J. B. and Fasshauer, D. (2010). A coiled coil trigger site is essential for rapid binding of synaptobrevin to the SNARE acceptor complex. J. Biol. Chem. 285, 21549-21559.

Wu, M. M., Llobet, A., and Lagnado, L. (2009). Loose coupling between calcium channels and sites of exocytosis in chromaffin cells. J. Physiol. 587, 5377-5391.

Yang, Y., and Gillis, K. D. (2004). A highly $\mathrm{Ca} 2+$-sensitive pool of granules is regulated by glucose and protein kinases in insulin-secreting INS-1 cells. J. Gen. Physiol. 124, 641-651.

Yang, Y., Udayasankar, S., Dunning, J. Chen, P., and Gillis, K. D. (2002). A highly Ca2+-sensitive pool of 
vesicles is regulated by protein kinase $\mathrm{C}$ in adrenal chromaffin cells. Proc. Natl. Acad. Sci. U.S.A. 99, 17060-17065.

Yizhar, O., and Ashery, U. (2008). Modulating vesicle priming reveals that vesicle immobilization is necessary but not sufficient for fusioncompetence. PLoS ONE 3, e2694. doi: 10.1371/journal.pone.0002694

Zenisek, D., Davila, V., Wan, L., and Almers, W. (2003). Imaging calcium entry sites and ribbon structures in two presynaptic cells. J. Neurosci. 23, 2538-2548.

Zhai, R. G., and Bellen, H. J. (2004). The architecture of the active zone in the presynaptic nerve terminal. Physiology (Bethesda) 19, 262-270.

Zhou, K. M., Dong, Y.M., Ge, Q., Zhu, D., Zhou, W., Lin, X. G., Liang, T., Wu, Z. X., and Xu, T. (2007). PKA activation bypasses the requirement for UNC-31 in the docking of dense core vesicles from C. elegans neurons. Neuron 56, 657-669.

Conflict of Interest Statement: The authors declare that the research was conducted in the absence of any commercial or financial relationships that could be construed as a potential conflict of interest.

Received: 17 May 2010; accepted: 17 January 2011; published online: 01 February 2011.
Citation: Stevens DR, Schirra C, Becherer $U$ and Rettig J (2011) Vesicle pools: lessons from adrenal chromaffin cells. Front. Syn. Neurosci. 3:2. doi: 10.3389/ fnsyn.2011.00002

Copyright $\odot 2011$ Stevens, Schirra, Becherer and Rettig. This is anopen-access articlesubject to an exclusive license agreement between the authors and Frontiers Media SA, which permits unrestricted use, distribution, and reproduction in any medium, provided the original authors and source are credited. 